\title{
TENSÕES E CONTRADIÇÕES DO TRABALHO POLIDOCENTE NA FORMAÇÃO DE PROFESSORES NA MODALIDADE A DISTÂNCIA: UMA ANÁLISE DO PROGRAMA NACIONAL ESCOLA DE GESTORES NA UNIVERSIDADE FEDERAL DE OURO PRETO
}

TENSIONES Y CONTRADICIONES DEL TRABAJO POLIDOCENTE EN LA FORMACIÓN DE PROFESORES EN LA EDUCACIÓN A DISTANCIA: UN ANÁLISIS DEL PROGRAMA NACIONAL ESCOLA DE GESTORES EN LA UNIVERSIDAD FEDERAL DE OURO PRETO

TENSIONS AND CONTRADITIONS OF POLYDOCENT WORK IN TEACHER TRAINING IN THE ON LINE EDUCATION: AN ANALYSIS OF THE PROGRAMA NACIONAL ESCOLA DE GESTORES AT THE FEDERAL UNIVERSITY OF OURO PRETO

RESUMO: O artigo analisa as tensões e contradições que permeiam o trabalho da equipe de formação do Programa Escola de Gestores, na Universidade Federal de Ouro Preto (PNEG/UFOP), no âmbito das ações de formação de professores que faziam parte da Política Nacional de Formação Continuada, até 2016. A partir da interação e dos processos pedagógicos e administrativos que conformam e vinculam esses sujeitos, foram realizadas 26 entrevistas formais com a equipe de formação que atuou no PNEG entre os anos de 2013 e 2016. As entrevistas evidenciam que as condições de trabalho e as questões orçamentárias revelam a fragilidade e a precariedade com que esse tipo de política tem sido implementada no Brasil.

PALAVRAS-CHAVE: Formação de professores. Educação a Distância. Trabalho docente.

RESUMEN: El artículo analiza las tensiones y contradicciones que permean el trabajo del equipo de formación del Programa Escola de Gestores, en la Universidad Federal de Ouro Preto (PNEG/ UFOP), en el marco de las acciones de formación de profesores que integravam la Política Nacional de Formación Continuada, hasta 2016. A partir de los procesos pedagógicos y administrativos que conforman y vinculan a esos sujetos, se

\footnotetext{
${ }^{1}$ Universidade Federal de Ouro Preto (UFOP), Ouro Preto - MG - Brasil. Professor-adjunto no Programa de Pós-graduação em Educação. Doutor em Educação. Membro do Núcleo de Avaliação Educacional (NAVE). E-mail: breynner@cead.ufop.br

${ }^{2}$ Universidade Federal de São Paulo (UNIFESP) - São Paulo - SP - Brasil. Técnica em Assuntos Educacionais. E-mail: lidia.martins30@gmail.com

${ }^{3}$ Universidade do Estado de Minas Gerais (UEMG) - MG - Brasil. Doutoranda em Educação. E-mail: adrianasantunesduarte@gmail.com
} 
realizaron 26 entrevistas con el equipo de formación que actuó en el PNEG entre los años de 2013 y 2016. Las entrevistas evidencian que las condiciones de trabajo y las cuestiones presupuestarias revelan la fragilidad y la precariedad con que ese tipo de política ha sido implementada en Brasil.

PALABRAS CLAVE: Formación de professores. Educación a distancia. Trabajo docente.

ABSTRACT: The article analyzes the tensions and contradictions that permeate the work of the training team of the Programa Escola de Gestores, at the Federal University of Ouro Preto (PNEG / UFOP), one of the programs that conform the National Policy for Continuing Education, until 2016. Based on the tasks, routines and perceptions of the team responsible for the training, 26 formal interviews were conducted with the professionals that took part of this team between 2013 and 2016. The interviews show that the working conditions and budgetary issues reveal the fragility and precariousness with which this type of policy has been implemented in Brazil.

KEYWORDS: Teaching training policies. On line Education. Teacher work.

\section{Introdução}

Pretende-se, nesse artigo, analisar algumas das tensões e contradições da política nacional de formação continuada de professores no Brasil a partir das percepções sobre o trabalho realizado pela equipe de formação do Programa Nacional Escola de Gestores da Educação Básica, ofertado pela Universidade Federal de Ouro Preto (PNEG/UFOP) na modalidade a distância.

Esta análise é resultado de uma das dimensões reveladas por uma pesquisa ${ }^{4}$ realizada com a equipe de formação do programa, cujo objetivo foi avaliar a mobilização dos saberes docentes dessa equipe e se (e como) contribuem para a conformação de um saber polidocente na educação a distância $(\mathrm{EaD})$. Foram realizadas entrevistas individuais em profundidade com profissionais que compuseram a equipe polidocente que atuou no PNEG no período de 2013 a 2015. As entrevistas foram transcritas e o conteúdo das mesmas foi analisado através do software NVivo®, que possibilitou a leitura e a classificação das fontes utilizadas, a partir do plano prévio das categorias analíticas.

Para tratar do trabalho polidocente na $\mathrm{EaD}$, toma-se como referência o conceito de polidocência adotado por Mill (2010, p. 17), compreendido como a "uma equipe de

${ }^{4} \mathrm{~A}$ pesquisa "Interação da equipe polidocente de formação na $\mathrm{EaD}$ : a experiência da especialização em Gestão Escolar da Universidade Federal de Ouro Preto (UFOP)" foi desenvolvida no âmbito do Programa de Bolsas de Iniciação Científica e Tecnológica Institucional da FAPEMIG (PROBIC-FAPEMIG/UFOP) e do Programa Institucional de Voluntários de Iniciação Científica (PIVIC/UFOP). 
educadores e assessores que - juntos, porém não na mesma proporção - mobilizam saberes de um professor". Para este autor, o trabalho realizado pelo docente a distância se estrutura de forma fragmentada, coletiva, colaborativa e cooperativa, onde quem ensina é o polidocente. Diferente do que se dá em uma sala de aula presencial, o trabalho docente virtual não é realizado por uma única pessoa, que se encarrega de todo o processo de formação. Ao contrário, um número diversificado de profissionais desempenha funções distintas, tornando o processo altamente fragmentado e especializado, constrangido pelo desenho institucional, responsável por definir as bases sob as quais o processo se estrutura (MILL, 2010). Ao assumir que a (poli)docência é uma atividade multideterminada, que depende de fatores institucionais, culturais e individuais, o objeto de investigação desta pesquisa são as tensões e contradições imanadas do trabalho da equipe de formação, tomando como ponto de partida a interação e os processos pedagógicos e administrativos que conformam e vinculam esses sujeitos.

$\mathrm{O}$ artigo está estruturado em cinco partes. A primeira parte apresenta uma breve discussão sobre a educação a distância no contexto da política de formação continuada de professores no Brasil. A segunda trata do PNEG na UFOP. Na terceira, os aspectos metodológicos são apresentados. A quarta analisa as tensões e contradições do trabalho polidocente no PNEG, seguida das considerações finais.

\section{A EaD no contexto das políticas de formação continuada de professores: o Programa Nacional Escola de Gestores}

No contexto das ações do Plano de Desenvolvimento da Educação (PDE) a partir de 2007, a Lei Federal $n^{\circ} 11.502$, nesse mesmo ano, alterou o enfoque de atuação da Coordenação de Aperfeiçoamento de Pessoal de Nível Superior (Capes) que, desde o ano de 1951, era a agência responsável pela indução da Educação Superior no país. Com a referida Lei, a Capes também assume o papel de implementar e instrumentalizar políticas públicas de formação inicial e continuada de professores da Educação Básica, com recursos do Fundo Nacional de Desenvolvimento da Educação (FNDE). Essa Lei prevê que:

Art. $2^{\circ}$ A Capes subsidiará o Ministério da Educação na formulação de políticas e no desenvolvimento de atividades de suporte à formação de profissionais de magistério para a educação básica e superior e para o desenvolvimento científico e tecnológico do País.

RIAEE - Revista Ibero-Americana de Estudos em Educação, Araraquara, v. 13, n. 2, p. 638-656, abr./jun., 2018. E-ISSN: 1982-5587. 
$\S 1^{\circ}$ No âmbito da educação superior, a Capes terá como finalidade subsidiar o Ministério da Educação na formulação de políticas para pósgraduação, coordenar e avaliar os cursos desse nível e estimular, mediante bolsas de estudo, auxílios e outros mecanismos, a formação de recursos humanos altamente qualificados para a docência de grau superior, a pesquisa e o atendimento da demanda dos setores público e privado.

$\S 2^{\circ}$ No âmbito da educação básica, a Capes terá como finalidade induzir e fomentar, inclusive em regime de colaboração com os Estados, os Municípios e o Distrito Federal e exclusivamente mediante convênios com instituições de ensino superior públicas ou privadas, a formação inicial e continuada de profissionais de magistério, respeitada a liberdade acadêmica das instituições conveniadas, observado, ainda, o seguinte: I na formação inicial de profissionais do magistério, dar-se-á preferência ao ensino presencial, conjugado com o uso de recursos e tecnologias de educação a distância; II - na formação continuada de profissionais do magistério, utilizar-se-ão, especialmente, recursos e tecnologias de educação a distância.

$\S 3^{\circ} \mathrm{A}$ Capes estimulará a valorização do magistério em todos os níveis e modalidades de ensino (BRASIL, 2007).

Entre as atividades desenvolvidas por aquela agência destacam-se a instituição do Programa Institucional de Bolsas de Iniciação à Docência (Pibid) e o Programa de Consolidação das Licenciaturas (ProDocência).

Após a reestruturação dos objetivos da Capes, em 2009 é lançado o Plano de Formação do Professor (PARFOR), institucionalizando e ampliando as funções da Rede Nacional de Formação Continuada de Professores da Educação Básica (RENAFOR). Dessa forma, a RENAFOR passa a abarcar um maior número de projetos de formação para serem implementados nas Instituições Públicas de Educação Superior, especialmente nas Universidades Federais, instituições financiadas pelo governo federal através do MEC. Os objetivos dessa nova Rede consistiam em promover um "conjunto de ações estratégicas de formação continuada, articuladas entre si com o objetivo de contribuir para a melhoria da formação de professores e alunos da educação básica" (GATTI; BARRETO; ANDRÉ, 2011, p. 56). Os programas que integraram a Rede Nacional de Formação Continuada como ações estratégicas do MEC nessa época foram, dentre outros: Pró-Letramento, Gestar II e Especialização em Educação Infantil.

A partir da reformulação da Rede em 2009, a Política Nacional de Formação de Professores foi redesenhada, voltando-se tanto para os profissionais que não possuíam titulação em nível superior, mas que estavam em pleno exercício da profissão docente, quanto para aqueles que, já graduados, demandavam qualificação profissional em nível de pós-graduação ou aperfeiçoamento. Assim, os cursos de formação continuada buscaram 
identificar as dificuldades dos profissionais no cotidiano escolar acreditando-se que, se fossem oferecidos conteúdos alinhados às demandas levantadas, produziriam, a partir do domínio de novos conhecimentos, mudanças tanto em sua postura profissional quanto em sua forma de agir socialmente, propiciando o compromisso entre o ensino de qualidade e a competência dos professores (GATTI, 2003; NUNES, 2001).

A Lei 13.005 de 2014, que instituiu o Plano Nacional de Educação (PNE) para o período de 2014 a 2024, quatro metas tratam especificamente da formação e do trabalho docente. As de número 17 e 18 voltam-se para a valorização profissional e para o estabelecimento de planos de carreira, enquanto as metas 15 e 16 dizem respeito a formação de professores da educação básica, inclusive na pós-graduação. Dentre as estratégias da meta 15, podem ser ressaltadas: elaboração de plano estratégico para orientar a atuação dos entes federados, com diagnóstico das necessidades de formação e da capacidade de atendimento por parte de instituições públicas e comunitárias; implementação de programas específicos para a formação de profissionais para as escolas do campo, de comunidades indígenas, quilombolas e de educação especial; implementação de cursos e programas para a formação específica na educação superior aos docentes com formação de nível médio na modalidade normal.

Para que tal formação em nível nacional fosse possível, a EaD foi a estratégia adotada pelo Governo Federal de modo a impulsionar o processo de qualificação docente no Brasil, especialmente no que se refere aos professores da educação básica pública (BELLONI, 2002; 2012).

Para compreendermos melhor o contexto no qual a EaD está inscrita no país, é preciso ter como base o Decreto ${ }^{\circ} 5.622$ de 19 de dezembro de 2005, que reconheceu a $\mathrm{EaD}$, em seu artigo $1^{\circ}$, como modalidade educacional “[...] na qual a mediação didático-pedagógica nos processos de ensino e aprendizagem ocorre com a utilização de meios e tecnologias de informação e comunicação, com estudantes e professores desenvolvendo atividades educativas em lugares ou tempos diversos" (BRASIL, 2005). Amparada e estimulada pela legislação, cresce no país a procura por cursos de formação inicial e continuada de professores oferecidos na modalidade a distância por instituições públicas e privadas (GATTI, 2008).

Caracterizado por um amplo território nacional, com grande diversidade cultural e especificidades regionais, as demandas por formação de professores no país exigem do governo federal estratégias em larga escala. É nesse contexto que a modalidade a distância 
on line mostra-se eficiente porque consegue alcançar uma gama muito grande de sujeitos dispersos geograficamente através da conexão à internet, criando um espaço de formação e uma rede de trocas entre os cursistas, mediados por um ambiente virtual de aprendizagem (AVA) e por docentes facilitadores, exigindo novas posturas de todos os envolvidos no processo educacional (MORAN, 2007). Na mesma direção, Orth et al. (2013) afirmam que:

[...] nessa sociedade, para ser cidadão do mundo é preciso se manter atualizado por meio da formação continuada. A Educação a distância $(\mathrm{EaD})$, ao utilizar recursos da web para suportar essa formação, permite aos cidadãos ampliar seus espaços de partilha e aprendizagem, ao mesmo tempo em que flexibiliza os momentos de estudo dos mesmos. Cria-se, desse modo, novas formas de atualizar-se, bem como se amplia o conhecimento [...] (p. 44).

A Universidade Aberta do Brasil (UAB) surge nesse contexto como um sistema virtual integrado por diversas instituições públicas de ensino superior que passam a oferecer cursos dirigidos, preferencialmente, à população que têm dificuldade de ingresso à formação superior. O objetivo da UAB era promover a formação inicial e continuada de professores, utilizando metodologias de educação a distância. Dessa maneira, "a UAB tornou-se um dos principais instrumentos de execução das políticas de formação em nível superior do Ministério da Educação (MEC), ao lado do Programa de Apoio aos Planos de Reestruturação e Expansão das Universidades Federais (Reuni) [...]” (GATTI; BARRETO; ANDRÉ, 2011, p. 63).
A institucionalização da formação superior de docentes a distância, concebida sob a forma de educação continuada que utiliza essas novas tecnologias, teve impulso na UAB, por meio do Programa Pró- Licenciatura, criado pelo MEC, em 2005, e dirigido a professores em serviço sem formação em nível superior ou atuando fora da área de sua formação (GATTI; BARRETO; ANDRÉ, 2011, p. 50).

É nesse contexto que ações voltadas para a formação continuada de professores com vistas ao fortalecimento dos sistemas de ensino e das escolas públicas brasileiras ganham contornos de política pública federal. A Secretaria de Educação Básica do Ministério da Educação (SEB/MEC) passa a investir, até 2015, consideráveis recursos voltados para a formação dos professores da educação básica através da $\mathrm{EaD}$. Dentre tais iniciativas estava o PNEG, que formava profissionais da equipe gestora de escolas 
Tensões e contradições do trabalho polidocente na formação de professores na modalidade a distância:

uma análise do Programa Nacional Escola de Gestores na Universidade Federal de Ouro Preto

públicas, priorizando aquelas com Índice de Desenvolvimento da Educação (IDEB) abaixo da média nacional ${ }^{5}$

Instituído em 2004, o Programa surgiu para implementar uma política de formação de gestores da educação básica que contemplasse a concepção do caráter público da educação e da busca de sua qualidade social, baseada nos princípios da gestão democrática e da educação inclusiva (BRASIL, 2009b). Suas ações estão concentradas em dois cursos de especialização na modalidade a distância: Gestão Escolar e Coordenação Pedagógica, com cargas horárias de 400 e 405 horas, respectivamente.

\section{O PNEG na UFOP}

Na UFOP, a implementação do PNEG iniciou-se em 2012, com o curso de especialização em Gestão Escolar. Entre 2012 e 2016, foram formadas três turmas, com aproximadamente 900 professores certificados.

Em relação ao PNEG na UFOP, o desenho da equipe assume que as atividades desempenhadas pelos formadores são compartilhadas e estruturadas a partir da polidocência, conforme definição de Mill (2010). Todos os integrantes dessa equipe eram remunerados por meio da concessão de bolsas ofertadas pelo Fundo Nacional de Desenvolvimento da Educação (FNDE) ${ }^{67}$. A Resolução CD/FNDE nº 24, de 16 de agosto de 2010, trata da regulamentação do pagamento das bolsas a programas de formação de professores, dentre eles o PNEG. O quadro 1 descreve os perfis e as atribuições de cada profissional que compõe a equipe polidocente do PNEG na Universidade.

${ }^{5}$ No ano de 2015, a crise econômica e política se aprofundam, culminando com a aprovação do processo de impeachment da Presidente Dilma Rousseff. O Vice-presidente Michel Temer passa a comandar uma nova coalizão política e implementa um conjunto de mudanças radicais para o país, marcadas por uma política de austeridade fiscal ainda mais severa. O contingenciamento do orçamento do MEC impacta significativamente nas políticas de formação inicial e continuada de professores da educação básica, que deixam de ser financiadas e operacionalizadas a partir de então.

${ }^{6} \mathrm{O}$ custeio do Programa se dá por meio de duas fontes de recursos: 1) bolsas do FNDE destinadas ao pagamento dos formadores, supervisores, coordenadores de sala ambiente e coordenação geral; 2) descentralização orçamentária destinada ao custeio de material de consumo, diárias, passagens, contratação de pessoa jurídica e de pessoa física, compreendendo a equipe de suporte tecnológico e administrativo.

${ }^{7}$ As atribuições e a remuneração dos profissionais envolvidos no PNEG é regulada pela Lei ${ }^{\circ} 11.273$, de 6 de fevereiro de 2006, Portaria n ${ }^{\circ}$ 1243, de 30 de dezembro de 2009 e resolução CD/FNDE n ${ }^{\circ}$ 24, de 16 de agosto de 2010. 
Quadro 1: Perfil e Requisitos dos bolsistas do PNEG

\begin{tabular}{|c|c|c|c|}
\hline Função & Perfil & Atribuição & Valores \\
\hline Coordenador Geral & \multirow{2}{*}{$\begin{array}{l}\text { Professor vinculado a } \\
\text { IES; } \\
\text { Experiência nas áreas } \\
\text { de Gestão Escolar com } \\
\text { conhecimento a respeito } \\
\text { de EaD com suporte em } \\
\text { Tecnologia Digital; } \\
\text { Titulação de Mestrado } \\
\text { ou Doutorado. }\end{array}$} & $\begin{array}{l}\text { Gestão do curso, definiçãa e } \\
\text { organização da equipe técnico- } \\
\text { pedagógica, coordenação dos } \\
\text { processos de avaliação do curso } \\
\text { e articulação da relação } \\
\text { IES/MEC. }\end{array}$ & $\mathrm{R} \$ 1.500,00$ \\
\hline $\begin{array}{l}\text { Coordenador } \\
\text { Adjunto }\end{array}$ & & $\begin{array}{l}\text { Auxiliar o coordenador geral na } \\
\text { gestão do curso. }\end{array}$ & $\mathrm{R} \$ 1.400,00$ \\
\hline $\begin{array}{l}\text { Coordenador de Sala } \\
\text { Ambiente }\end{array}$ & $\begin{array}{l}\text { Experiência na docência } \\
\text { com suporte em } \\
\text { Tecnologia Digital; } \\
\text { Experiência na área } \\
\text { específica da sala } \\
\text { ambiente; } \\
\text { Titulação de Mestrado } \\
\text { ou Doutorado }\end{array}$ & $\begin{array}{l}\text { Seleção dos conteúdos e } \\
\text { atividades da disciplina. }\end{array}$ & $\mathrm{R} \$ 1.400,00$ \\
\hline $\begin{array}{l}\text { Supervisor de curso } \\
\text { (Geral e Pedagógico) }\end{array}$ & Não especificado & 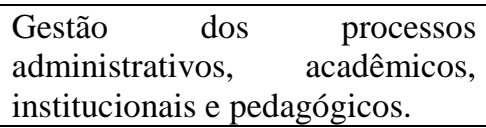 & $\mathrm{R} \$ 1.100,00$ \\
\hline $\begin{array}{c}\text { Professor de Turma } \\
\text { (Professor } \\
\text { Pesquisador) }\end{array}$ & $\begin{array}{l}\begin{array}{l}\text { Experiência na } \\
\text { específica da }\end{array} \text { área } \\
\text { ambiente; } \\
\text { Titulação de mestrado } \\
\text { ou doutorado. }\end{array}$ & $\begin{array}{l}\text { Gestão acadêmica e mediação } \\
\text { dos conteúdos junto à sua } \\
\text { turma/polo, juntamente com o } \\
\text { assistente de turma; } \\
\text { Orientação dos Trabalho de } \\
\text { Conclusão de Curso (TCC). }\end{array}$ & $\mathrm{R} \$ 1.300,00$ \\
\hline $\begin{array}{l}\text { Assistente de Turma } \\
\text { (Tutor) }\end{array}$ & $\begin{array}{l}\text { Experiência na área de } \\
\text { educação; } \\
\text { Titulação } \\
\text { especialização; } \\
\text { Experiência em cursos a } \\
\text { distância com suporte } \\
\text { em tecnologia digital. }\end{array}$ & $\begin{array}{l}\text { Gestão acadêmica e mediação } \\
\text { dos conteúdos junto à sua turma; } \\
\text { atendimento presencial no polo. }\end{array}$ & $\mathrm{R} \$ 765,00$ \\
\hline
\end{tabular}

Fonte: Adaptado de Resolução/CD/FNDE nº 24, de 16 de agosto de 2010. (BRASIL, 2009b, p. 2428)

Por se tratar de uma equipe polidocente, o papel desempenhado por esses professores é uma questão a ser analisada mais profundamente. Esse fazer coletivo e colaborativo vincula diferentes atores e processos, em diferentes tempos e espaços. Dadas as especificidades do trabalho, sua dimensão formativa, a virtualidade da interação e os constrangimentos institucionais que definem os processos pedagógicos e administrativos, tensões e contradições naturalmente emergem.

É preciso, então, assimilar as condições em que o trabalho polidocente é realizado na prática uma vez que a combinação desses elementos constitui o fazer polidocente no cotidiano da formação, razão pela qual importa compreender como esses aspectos se 
combinam e quais são os desdobramentos que essa alquimia produz, o que será aprofundado na seção posterior aos aspectos metodológicos.

\section{Aspectos Metodológicos}

Foram realizadas 26 entrevistas individuais em profundidade com a equipe polidocente do programa no período de 2013 a 2015: 10 professores de turma (PT), oito assistentes de turma (AT), três professores coordenadores de sala ambiente (PCSA), três supervisores pedagógicos (SP) e dois membros da equipe de suporte administrativo e tecnológico (SA/ST). As entrevistas foram realizadas a partir de um roteiro semiestruturado, elaborado com questões que comtemplassem as seguintes dimensões: (i) experiência docente e trajetória profissional; (ii) percepções sobre a formação continuada de professores na modalidade a distância; (iii) rotinas e estratégias de formação e interação e (iv) percepções sobre o desenho institucional implementado pela UFOP.

A análise das entrevistas forneceu cinco macro categorias: (i) autonomia e concepções sobre o desenho de formação do PNEG; (ii) percepções sobre a EaD; (iii) política nacional de formação docente à distância; (iv) saberes docentes; (v) trabalho polidocente. A partir disso, cada uma dessas categorias foi analisada com a assistência do software NVivo®, ferramenta que possibilita a leitura e a classificação das fontes utilizadas, a partir daquelas cinco dimensões. $O$ software permite a elaboração de análises qualitativas a partir de conceitos e classificações previamente identificados pelo pesquisador.

O NVivo® funciona como um codificador: a partir das categorias previamente elencadas, o programa realiza a codificação do material (no caso dessa pesquisa, as transcrições das entrevistas), possibilitando uma separação mais robusta dos trechos que exemplificam tais categorias, e tornando este trabalho mais ágil, em comparação com a alternativa manual. A rigor, portanto, a lógica de funcionamento do software é bastante simples e mecânica. Este procedimento de codificação é o cerne do trabalho no NVivo® e embasa todos os demais procedimentos a serem adotados, uma vez que, para que qualquer parametrização seja feita, é preciso que os dados já estejam codificados segundo as categorias.

As categorias analíticas empregadas no estudo foram operacionalizadas a partir de "nós" no software NVivo®. Os "nós" são os códigos segundo os quais o material de 
evidências disponíveis foi codificado. A Tabela 1 sistematiza quantitativamente os "nós" referentes à primeira categoria. Na segunda coluna, as fontes referem-se às entrevistas (em um total de 26, 20 foram utilizadas para essa categoria). Na terceira, os trechos indicam os 312 excertos que foram codificados nas 20 entrevistas. 92 trechos codificados fizeram referência direta ou indireta ao Trabalho Polidocente, revelando sua centralidade para a política de formação de professores no Brasil.

Tabela 1: Recorrência da categoria Autonomia, por fontes e trechos codificados

\begin{tabular}{|c|c|c|}
\hline Categoria & Fontes codificadas & Trechos codificados \\
\hline Trabalho polidocente & 20 & 312 \\
\hline Características do trabalho na $\mathrm{EaD}$ & 11 & 19 \\
\hline Negativas & 9 & 12 \\
\hline Fragmentação & 3 & 3 \\
\hline Hierarquização & 1 & 1 \\
\hline Intensificação & 8 & 12 \\
\hline Positivas & 3 & 3 \\
\hline Flexibilidade de local e horário & 4 & 4 \\
\hline Prática pedagógica & 20 & 52 \\
\hline Formas e estratégias de interação com alunos & 15 & 25 \\
\hline Potenciais e dificuldades & 13 & 21 \\
\hline Momentos de formação & 18 & 32 \\
\hline Reuniões presenciais & 9 & 10 \\
\hline Reuniões virtuais & 5 & 5 \\
\hline Sala de interação pedagógica & 12 & 16 \\
\hline Organização do trabalho pedagógico com o aluno & 4 & 4 \\
\hline Correção de atividades & 4 & 4 \\
\hline Feedback & 4 & 4 \\
\hline Trabalho em equipe & 14 & 28 \\
\hline Divisão de tarefas & 9 & 13 \\
\hline Colaboração-cooperação & 1 & 1 \\
\hline Interação com a equipe polidocente & 15 & 25 \\
\hline Interação com professores conteudistas & 5 & 6 \\
\hline Interação entre PTs e ATs & 6 & 11 \\
\hline Interação entre PTs-ATs e alunos & 1 & 1 \\
\hline
\end{tabular}

Fonte: elaborado pelo autor, a partir dos dados extraídos do NVivo.®

\section{Tensões e contradições do trabalho da equipe polidocente na UFOP}

\section{Trabalho polidocente: fragilização profissional}


As pressões por qualidade e competitividade impostas pelo mundo globalizado associadas às necessidades de renda e subsistência impõem aos docentes jornadas de trabalho cada vez maiores e/ou a adesão a contratos de trabalho mais intensos e exigentes. De modo geral, os profissionais entrevistados trabalhavam em outras instituições de ensino (escolas da educação básica, faculdades particulares ou universidades públicas), onde suas garantias trabalhistas estavam asseguradas. Ainda que essa fosse a principal fonte de renda da maioria dos formadores entrevistados, percebeu-se que a complementação salarial era uma das motivações que orientaram as decisões dos profissionais em fazer parte da equipe de formação. Isto ocorre porque "os ganhos salariais [dos professores] são, em média, baixos para configurar a principal fonte de renda do grupo familiar" (MILL, 2006, p. 215).

Duas entrevistas com professoras de turma evidenciam a "contratação" enquanto bolsistas como estratégia para a complementação salarial. O terceiro trecho ilustra o peso que a remuneração complementar tem em relação ao ganho total do formador, além da sugestão de que o valor passa a fazer parte de seu orçamento pessoal e/ou familiar:

Me disseram que existia essa possibilidade de vaga [no PNEG] e se eu tinha interesse, que era apenas uma bolsa, mas que tinha um processo de seleção. É uma forma de complementar a renda (PT2).

Não é um concurso público, não é um professor concursado para estar na UFOP, mas é uma organização de bolsas e que permite a entrada de pessoas desta forma, melhorando nosso salário (PT5).

[Se] o financeiro ia fazer falta se eu saísse? Claro, com certeza. Eu não dependo do dinheiro da bolsa para sobrevivência, mas esse dinheiro me proporciona uma condição melhor. [Se] eu quero programar uma viagem, eu conto com aquele dinheiro (PT6).

A questão do pagamento dos professores formadores é um aspecto que merece destaque nessa pesquisa. O pagamento sob a forma de "bolsa", conforme detalhado no Quadro 1, denota a evidente precarização docente no PNEG e em vários outros programas de formação continuada coordenados pelo MEC. Como afirma Oliveira et al,

O financiamento desse programa esbarra em uma questão delicada: as bolsas pagas aos formadores, tutores a distância e tutores presenciais são muito baixas, produzindo desincentivos que prejudicam a gestão local das ações $(2014$, p. 24).

Conforme apresentado no Quadro 1, os valores das bolsas pagas pelo FNDE são diferenciados de acordo com as funções executadas no curso. Para cada função (professor 
ou assistente de turma), exige-se formação e experiência profissional específicas para compor um perfil qualificado, além da disponibilidade de vinte horas semanais para realização das atividades do curso. No caso específico do assistente de turma, vale ressaltar que doze das vinte horas semanais deveriam ser cumpridas presencialmente no polo de apoio, para atendimento dos alunos. As bolsas, por sua vez, não asseguram vínculo empregatício com a instituição, destituindo estes profissionais de qualquer tipo de direito trabalhista. A conjugação desses fatores - exigência de qualificação e precariedade do vínculo trabalhista associada aos baixos valores pagos - revela uma incoerência desse tipo de política, que concorre para uma desvalorização dos profissionais que atuam na EaD. Esse aspecto é reforçado por Mill (2006) quando considera que:

as contratações de profissionais para educação no Brasil, mesmo no âmbito das universidades públicas, caracterizam-se por serem temporárias, de tempo parcial, com salários e condições de trabalho inferiores aos do presencial e, por vezes, sem alguns direitos garantidos (p. 136).

Além do vínculo desses docentes ser precário, por não garantir nenhum benefício ou direito trabalhista, nem mesmo o pagamento é assegurado de forma regular. A conjuntura econômica e a crise orçamentária enfrentadas pelo Governo Federal desde 2014 afetaram as ações de formação de professores, incluindo o PNEG em duas grandes frentes. A primeira diz respeito à interrupção no fluxo de ofertas de novas turmas, comprometendo a eficiência e a eficácia de uma das políticas educacionais que orienta a ação do MEC em nível nacional. Tal interrupção é agravada a partir de 2016, com a mudança da agenda governamental em função do governo de Michel Temer, também refletida no MEC. A segunda está relacionada às bolsas dos formadores que atuavam em cursos nesse período (2014-2016). Por causa do contingenciamento orçamentário, o pagamento dessas bolsas sofreu sucessivos atrasos, contribuindo para o cenário de incerteza e consequente precarização do trabalho. Ao se referirem a um período de aproximadamente quatro meses em que houve atraso no pagamento das bolsas no ano de 2015, as professoras apontaram alguns reflexos deste atraso em suas práticas, ao ressaltarem que:

As pessoas [referindo-se aos formadores] estão mais dispersas. Pode ser por causa dos atrasos das bolsas (AT2).

Você se dispõe a trabalhar para estar atuando, então é mais que obrigação do Governo Federal pagar! [...] É mesmo muito complicado trabalhar e não receber, mas você tem certeza que vai ser depositado na 
sua conta. No fim, nós temos certeza e também tem outra prerrogativa: você está trabalhando no curso porque você quer, é uma escolha que você faz, mas esse trabalho tem que ser valorizado! (PT3).

Tal situação gerou insegurança aos professores, intensificada pela falta de informações do MEC sobre a regularização dos pagamentos, cujo atraso era quase sempre justificado pelo contingenciamento de recursos no Ministério. Essas questões relativas à fragilização do trabalho polidocente evidenciam uma contradição da própria política de formação continuada de professores na modalidade a distância: nas condições em que o Programa Escola de Gestores e demais programas e ações são viabilizados, não estaria o Governo se valendo da precarização das condições de trabalho dos formadores para promover uma qualificação de professores/gestores?

\section{Trabalho polidocente: intensificação profissional}

Outro fator importante é a intensificação do trabalho dos docentes na EaD. Por dedicarem-se muitas horas ao trabalho de correção de atividades e de feedback aos alunos através do Ambiente Virtual de Aprendizagem e outras tecnologias de comunicação virtual, Hypolito (2011) afirma que este é um trabalho que pode ser muito estafante, ainda que realizado em casa. Um excerto de uma entrevista corrobora essa afirmação:

E a correção, dependendo da atividade, consome muito tempo que você tem que ser justo. Você tem que ter um critério para uma turma de quarenta alunos, de repente você vai fazer uma correção de textos com cinco laudas... se você for corrigir quarenta isso demanda um tempo [...] e às vezes até a carga de leitura de material também, por exemplo, eu precisava me inteirar do conteúdo e são várias atividades (PT4).

Essa dinâmica de trabalho exige do indivíduo mais e mais horas do seu tempo (BLIKSTEIN; ZUFFO, 2006), pois a docência virtual exige mais do professor em termos de dedicação e de investimento de tempo. Em meio a essa conjuntura, junto ao grupo investigado, percebeu-se como se dava essa intensificação do trabalho docente na EaD. Para os entrevistados, a intensificação do trabalho estava diretamente relacionada ao número de alunos matriculados nas disciplinas e o tempo destinado à correção de atividades. 
Na EaD, trabalho muito, muito mesmo, muito mais. Na verdade, é o seguinte: nesse trabalho agora são vinte e três alunos que postaram. Cada trabalho tem, no mínimo, quatro laudas. Então, eu não gasto menos de uma hora para corrigir. [Isso] se eu for pegar só para ler! Porque eu gosto de ler mais de uma vez e gosto de fazer correções dentro do próprio texto e já faço o feedback. Eu gasto mais de uma hora, então, só com esses vinte e três eu gasto vinte e três horas. Então não são vinte horas. Quando eu tinha cinquenta alunos, cinquenta horas (PT5).

Eu acho que todas as nossas ações no [ensino] a distância são mais intensas que no presencial justamente para diminuir essa distância que tem entre o aluno (AT3).

Mesmo que o trabalho ocorra em casa na maioria do tempo, há uma intensificação da jornada devido à grande demanda por parte de materiais usados nas plataformas ou correção de atividades que podem tomar um tempo considerável, até mesmo invadir a vida particular dos docentes:

Eu chego em casa e trabalho umas quinze horas. Eu trabalho na escola, na faculdade e na UFOP. Eu tenho colegas aqui que dobram na escola. Eu não dobro, então eu fico à tarde em casa trabalhando, preparando as aulas, orientando (PT3).

Mill e Fidalgo revelam que no trabalho docente realizado pela internet, ocorre uma demanda para que o professor esteja o tempo todo disponível aos seus alunos. A educação a distância e seu vínculo acabam:

[...] fazendo muitas vezes com que docentes confundam este trabalho como altamente qualificado quando, em verdade, é muito mais intensificado e precarizado, pois trabalha-se a qualquer dia e hora, com um número absurdo de estudantes, correções de trabalhos, fóruns de discussão, mensagens e com atendimento individualizado (HYPOLITO, 2011, p. 13).

No PNEG, as atribuições são mais sentidas pelos assistentes de turma que dividem, com os professores de turma, as atividades a serem corrigidas, mas recebem um valor monetário de bolsa bem menor. Essa intensificação foi percebida posteriormente à implementação da segunda turma do curso na UFOP, quando a equipe de coordenação e supervisão integrou os assistentes de turma às atividades de correção, de modo a envolvêlos também no aspecto propriamente pedagógico da formação. Essa mudança foi percebida pelas professoras: 
Na primeira turma o assistente não tinha tanta responsabilidade. Os de hoje tem bastante para a bolsa que eles ganham. $O$ assistente divide as tarefas e ainda tem que cumprir o horário no polo. Realmente eu acho que estão corajosos (AT2).

No início, a gente não fazia correção de atividades, aí depois acho que foram mudando algumas coisas e a gente começou a dividir. A hora que a gente assustou já estava fazendo funções equivalentes ao de professor de turma (AT5).

As condições do trabalho realizado pelos docentes na EaD reforçam a ideia de intensificação e precarização em função dos seguintes aspectos: (i) a sobrecarga de trabalho; (ii) a grande quantidade de alunos por turma e (iii) a baixa remuneração. A combinação entre tempo e espaço alocados para o trabalho online são vistos por muitos docentes como vantajosa, uma vez que permite certa autonomia e flexibilização da rotina e da execução dos processos. Em contrapartida, ocorre uma intensificação da jornada de trabalho, muitas vezes não percebida por esses docentes. Os fragmentos a seguir confirmam esse conflito implícito no discurso de uma professora:

Quanto à minha organização pessoal, à flexibilidade de horário, eu tenho uma dedicação de horas, mas é uma dedicação flexível em que eu posso me organizar para trabalhar na hora que eu tenho condição e às vezes durante a semana eu não tenho disponibilidade eu organizo para, no fim de semana, cumprir algumas tarefas. Então essa flexibilidade ajuda muito (AT3).

Na primeira turma eu passava quase vinte e quatro horas, porque às vezes você olhava e estavam todos os trabalhos respondidos, todos os trabalhos corrigidos, fórum comentado, mas a plataforma está ali, [por isso] eu vou dar uma olhada, eu respondia quase que instantaneamente todos os e-mails [e] todas as mensagens que eu recebia (PT1).

Carneiro (2002) reforça essa questão e alega que essa flexibilização é uma ilusão, uma vez que o tempo pode gerar, na verdade, mais trabalho. Para o autor, "na realidade, o que ocorre é que ficamos disponíveis para o trabalho o tempo todo e entramos num malabarismo diário, quase sem descanso, de intercalar compromissos profissionais com domésticos" (p. 28). No excerto de três entrevistados, pode-se perceber essa interferência:

Era uma atividade por semana, então foi muito pesado para a gente conseguir ler tudo e corrigir e postar a nota. Então eu achei assim que foi muito tumultuado. A supervisora às vezes falava: "vocês precisam trabalhar vinte horas por semana", mas eu trabalhava muito mais de cinquenta! Então a gente teve uma dedicação sábado, domingo e feriado para dar conta (PT5).

RIAEE - Revista Ibero-Americana de Estudos em Educação, Araraquara, v. 13, n. 2, p. 638-656, abr./jun., 2018. E-ISSN: 1982-5587. 
Eu não tenho feriado, não tenho sábado, não tenho domingo, não tenho noite talvez. Eu posso não cumprir aquele horário semanal, mas eu compenso isso no final de semana. Eu entro para olhar o que está acontecendo, se tem alguma, alguém questionando, mas eu não cumpro aquele horário à risca na semana porque eu sei que no final de semana é o momento que o aluno tem para acessar. Eu dou mais assistência ao aluno no final de semana porque ele está em casa, é o tempo que ele tem para acessar. Então eu organizo o meu horário dessa forma (AT3).

Você está ali para ter uma renda a mais, você precisa desse dinheiro, você aceitou trabalhar, você tem que cumprir as suas funções... Isso é muito sério! Quando eu não estou dando conta de fazer isso da forma que deve ser feito, eu falo abertamente que é muito ruim. A pessoa precisa da sua orientação e muitas vezes por causa da sobrecarga de trabalho a gente acaba pegando, mas não dá conta (PT2).

\section{Considerações finais}

No se que refere à política de formação continuada de professores na modalidade a distância, o caráter ambíguo da valorização do profissional docente - visto como personagem central no processo de formação, mas cujo vínculo é precário e a remuneração é baixa - revela a fragilidade com que esse tipo de política tem sido implementada no Brasil. Especificamente no curso em questão, a análise das entrevistas com professores e assistentes de turma - que integram a equipe polidocente do curso - revelou algumas das tensões e contradições inerentes ao processo formativo virtual, haja vista os reflexos da precarização docente sentidos em seu trabalho, especialmente neste contexto de contigenciamento orçamentário, orientado por uma severa política fiscal.

Em outras palavras, as políticas de formação e qualificação profissional de professores implementadas pelo MEC requerem a constituição de equipes docentes que desempenham o papel de acompanhar e formar os professores-cursistas. Formadas por professores externos aos quadros das Universidades, tais equipes serão remuneradas, em sua grande maioria, através de bolsas pagas pelo FNDE que, dentre suas finalidades, foi constituído para fortalecer a carreira docente e contribuir na recomposição salarial dos profissionais da educação. ${ }^{8}$

Nesse sentido, a bolsa não faz nem uma coisa, nem outra: enfraquece a carreira porque os valores são muito baixos, reforçando os desincentivos em se tornar professor. Tal assimetria, ao invés de ser reduzida, é ampliada, contribuindo negativamente para a

\footnotetext{
${ }^{8}$ Apenas para fins de comparação, o salário mínimo vigente é de $\mathrm{R} \$ 880,00$. As bolsas em tela não sofrem reajuste desde 2011.
} 
valorização do trabalho do professor. Ai está uma das tensões e contradições da política: valer-se da fragilização e precarização da equipe de formação para promover a qualificação dos cursistas, também docentes, reproduzindo um círculo vicioso que, ao fim e ao cabo, piora a condição docente no Brasil.

No que se refere ao PNE, o quadro de recessão econômica que se instalou no país em seguida à aprovação do plano, associado às alterações no cenário político resultantes do impeachment da presidente Dilma Rousseff em 2016, são elementos que permitem supor que o cumprimento das metas, previstas para 2024, não será efetivado, colocando novamente em discussão o cumprimento do artigo 62 da $\mathrm{LDB}^{9}$. Da mesma forma, a Emenda Constitucional No. 95, aprovada em 15 de dezembro de 2016, que institui o chamado "Novo Regime Fiscal" no âmbito dos Orçamentos Fiscal e da Seguridade Social da União, altera a relação entre as receitas e as despesas públicas, agravando ainda mais o investimento do Estado nas áreas da saúde e da educação.

Do ponto de vista da implementação e operacionalização das ações de formação que estão a cargo das universidades públicas (dentre elas, o PNEG), o contingenciamento orçamentário e a interrupção das ofertas a partir de 2016 desarticulam, no nível local, as equipes de formação e produzem incertezas e desincentivos para que os professores se qualifiquem, fragilizando ainda mais os docentes, os municípios e Estados que dependem dessa rede para viabilizar seus projetos de formação. Nova contradição e tensão se revelam: a inconsistência da política é perversa e torna-se ainda mais perversa quando a questão orçamentária se sobrepõe à política educacional, comprometendo ainda mais o fortalecimento da profissão docente no Brasil.

\section{REFERÊNCIAS}

BRASIL. Lei $\mathbf{n}^{\mathbf{0}}$ 11.273, de 6 de fevereiro de 2006. Autoriza a concessão de bolsas de estudo e de pesquisa a participantes de programas de formação inicial e continuada de professores para a educação básica. Disponível em: <http://www.planalto.gov.br/ccivil_03/_Ato2004-2006/2006/Lei/L11273.htm>. Acesso em: 2 mar. 2016.

BRASIL. Programa Nacional Escola de Gestores. Projeto do curso de especialização em Gestão Escolar (lato sensu). Brasília: MEC/SEB, 2009b.

${ }^{9} \mathrm{O}$ referido artigo dispõe que a formação dos docentes para atuar na educação básica deve ser feita prioritariamente em nível superior.

RIAEE - Revista Ibero-Americana de Estudos em Educação, Araraquara, v. 13, n. 2, p. 638-656, abr./jun., 2018. E-ISSN: $1982-5587$. 
BRASIL. Resolução/CD/FNDE n 24 , de 16 de agosto de 2010. Estabelece orientações e diretrizes para o pagamento de bolsas de estudo e de pesquisa a participantes dos programas de formação inicial e continuada de professores e demais profissionais de educação, implementados pela Secretaria de Educação Básica do Ministério da Educação (SEB/MEC) e pagas pelo FNDE. Diário Oficial da União - DOU, de 17-8-2010, Seção 1, págs. 11 a 14.

BELLONI, M. L. Ensaio sobre a educação a distância no Brasil. Educação \& sociedade, v. 23, n. 78, p. 117-142, 2002.

BELLONI, M. L. Educação a distância. $6^{a}$ ed. Campinas, SP: Autores Associados, 2012. BLIKSTEIN, P.; ZUFFO, M. K. As sereias do ensino eletrônico. In: SILVA, M. (Org.). Educação online: teorias, práticas, legislação e formação corporativa. 2. ed. São Paulo: Loyola, 2006. p. 25-40.

CARNEIRO, R. Informática na educação: representações sociais do cotidiano. Cortez Editora, 2002.

CORTINHAS, M. S. Tutoria Presencial de polo de Apoio em EAD: um diferencial para a Educação a Distância. EDUCERE. Anais... Curitiba, 2008.

GATTI, B. A. Análise das políticas públicas para formação continuada no Brasil, na última década. Revista Brasileira de Educação, v. 13, n. 37, jan./abr. 2008.

GOMES, A. M.; DOS SANTOS, A. L. F.; DE MELO, D. B. L. Escola de Gestores: política de formação em gestão escolar. Revista Brasileira de Política e Administração da Educação, v. 25, n. 2, 2009.

HYPOLITO, A. M. Reorganização gerencialista da escola e trabalho docente. Educação: Teoría e prática, v. 21, n. 38, p. 59-78, 2011.

MILL, D. Estudos sobre os processos de trabalho em sistemas de educação a distância mediada por tecnologias da informação e da comunicação. Belo Horizonte, 2002. Dissertação (Mestrado em Educação) - Faculdade de Educação da Universidade Federal de Minas Gerais, 2002.

MILL, D.; FIDALGO, F. Espaço, tempo e tecnologia no trabalho pedagógico: redimensionamento na Idade Mídia. Revista Brasileira de Estudos Pedagógicos, Brasília, v. 88, n. 220, p. 421-444, 2007.

MILL, D.; SANTIAGO, C.; VIANA, I. Trabalho docente na educação a distância: condições de trabalho e implicações trabalhistas. Revista Extra-Classe, v. 1, n. 1, 2008. 
MILL, D. R. S. RIBEIRO, L. R. C; OLIVEIRA, M. R.G. (Orgs.). Polidocência na

educação a distância: múltiplos enfoques. São Carlos: EdUFSCar, 2010.

MORAN, J. M. A educação que desejamos: novos desafios e como chegar lá. Papirus Editora, 2007.

MORAN, J. M. O ensino superior a distância no Brasil. Educação \& Linguagem, v. 12, n. 19, p. 17-35, jan./jun. 2009.

\section{Como referenciar este artigo}

OLIVEIRA, Breynner Ricardo de.; MARTINS, Lídia Gonçalves.; DUARTE, Adriana Otoni. Tensões e contradições do trabalho polidocente na formação de professores na modalidade a distância: uma análise do Programa Nacional Escola de Gestores na Universidade Federal de Ouro Preto. Revista Ibero-Americana de Estudos em Educação, Araraquara, v. 13, n. 2, p. 638-656, abr./jun., 2018. E-ISSN: 1982-5587. DOI: 10.21723/riaee.v13.n2.2018.11063

Submissão em: 20/11/2017

Aprovação final em: 20/04/2018 